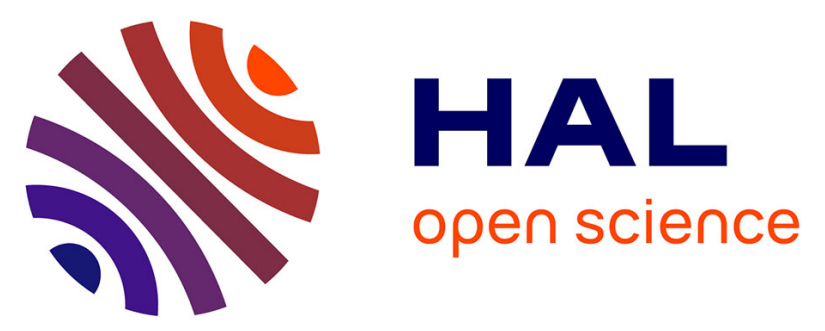

\title{
Effectiveness of Production Planning and Control (PPC) in a Baby Fashion Cluster, Under the Prism of Paraconsistent Logic
}

Elizangela Lima, Fabio Papalardo, Jose B. Sacomano, Priscila Facciolli Tavares, Esdras Barboza

\section{To cite this version:}

Elizangela Lima, Fabio Papalardo, Jose B. Sacomano, Priscila Facciolli Tavares, Esdras Barboza. Effectiveness of Production Planning and Control (PPC) in a Baby Fashion Cluster, Under the Prism of Paraconsistent Logic. IFIP International Conference on Advances in Production Management Systems (APMS), Sep 2016, Iguassu Falls, Brazil. pp.162-169, 10.1007/978-3-319-51133-7_20 . hal01615748

\author{
HAL Id: hal-01615748 \\ https://hal.inria.fr/hal-01615748
}

Submitted on 12 Oct 2017

HAL is a multi-disciplinary open access archive for the deposit and dissemination of scientific research documents, whether they are published or not. The documents may come from teaching and research institutions in France or abroad, or from public or private research centers.
L'archive ouverte pluridisciplinaire HAL, est destinée au dépôt et à la diffusion de documents scientifiques de niveau recherche, publiés ou non, émanant des établissements d'enseignement et de recherche français ou étrangers, des laboratoires publics ou privés. 


\title{
Effectiveness of Production Planning and Control (PPC) in a Baby Fashion Cluster, under the prism of Paraconsistent Logic
}

\author{
Elizangela Maria Menegassi de Lima ${ }^{1,2}$, Fabio Papalardo ${ }^{2}$, Jose B. Sacomano ${ }^{2}$, \\ Priscila Facciolli Tavares ${ }^{2}$, and Esdras Jorge Santos Barboza ${ }^{2}$ \\ 1 Paranaense University, Umuarama, Brazil \\ menegassi@unipar.br \\ 2 Paulista University, Sao Paulo, Brazil
}

\begin{abstract}
This research aimed at understanding relevant aspects of production planning and control of a baby wear cluster in Terra Roxa, Paraná State, Brazil, employing the Paraconsistent Logic as an analysis. In the methodology, a descriptive approach with quantitative and qualitative procedures has been opted for, making use of data collection tools such as survey, which is appropriate for this kind of approach. Results show that the effectiveness of Production Planning Control in the Cluster is viable under the Prism of Paraconsistent Logic.
\end{abstract}

Keywords: Cluster - Production planning and control $\cdot$ Paraconsistent logic $\cdot$ Competition $\cdot$ Baby fashion

\section{Introduction}

Production management comprehends the activities involved in the transformation process of products or services, corresponding to the set of actions of planning, management and control of operational activities. For the adequacy and longevity of a company or process in the economically profitable and efficient market it is necessary to provide basic conditions for the introduction in current concepts $[1,2]$. In an intense and competitive scenario, the products and services depend on the quality of the organizational operation $[2,3]$.

Reuter and Brambring [4] state that excellence in production planning and control (PPC) is the main pre-requirement for the managing of the production system.

In that sense, the productive process has to offer flexibility, in the process of solutions and alternative adapted to the needs of the company. The management of operations is responsible for the planning and control of the use of production resources to develop products with excellence, enabling the company's competition and longevity in the market [5].

The study of operations and production control seeks to define and employ the tools, methods and instruments viable to the generation of positive results in organizational life development. The generation of results derives from consumer's (i.e. end user's), satisfaction and loyalty; 
This planning reflects on the production costs and deadlines. The more efficient and effective the planning is, the better the cluster PPC development will be. The knowledge of the elements of the production, as for providing information for the many areas of the organizations manufacturing system aid the operations for the achievement of excellence and desirable finished products $[5,6]$.

Therefore, the main objective of this study is understand the relevant aspects of the PPC in a Baby Fashion cluster, making use of Paraconsistent Logic with analysis tools. This tools is essential for the efficiency of the planning and control in the cluster enabling the achievement of goals with shorter deadlines and smaller costs.

\section{Literature Review}

\subsection{Production Planning, Programation and Control}

The PPC is one of the most important administrative operations from the perspective of productive activities. Planning and subsequently control, as the name implies, is not an easy task, but rather a very complex one, because it takes into consideration a relevant number of variables $[1,5]$.

One of the biggest PPC difficulties, rather than planning, is controlling production because disturbances and incidents common in a production process, can hamper the original program, causing delays and additional costs. In order to make this PPC viable it is necessary to study its evolution along the time and the causes which triggered the changes. Such causes will indicate the influence of all the sectors involved in the production process, and how these sectors interact $[1]$.

PPC is considered an operation which involves areas of a company or a project to achieve the organizations productive goals, which seek to systematize its processes considering the effectiveness and efficiency aspects, that is to say, PPC has as its essence the carrying on a program of coordinate actions in order to obtain the smallest cost within the shortest possible deadline in the making of a product or performing a service, and subsequently, control those actions so that it sticks to the original program as much as possible $[1,5]$.

As time passes by, according to technological developments, the concept of PPC has been changing, also. The most important aspect of the development and maintenance context of a production control and planning system may be the Constant change in its competitive environment, and such changes vary from technological to the strategic and legal fields [7].

With the constant technological development and a great set of market strategies and legislation variation due to globalization, the Production planning becomes more and more complex, with a number of variables which increases systemically, being some of those variables are unchanging or imponderable [8].

Regardless of the kind of manufacturing, or manufacturing system, the Planning is an essential factor for the task to succeed. Traditional planning systems 
such as ERP among others, are no more sufficient for a safe and assertive planning [9].

\subsection{Paraconsistent Logic Annotated}

The paraconsistent logic is capable of manipulating inconsistent information systems without running the risk of trivialization. In the paraconsistent logic there are formulas $\mathrm{A}$ such that from $\mathrm{A}$ and $\neg \mathrm{A}$ no formula $\mathrm{B}$ comes, that is to say, there is a formula B of a set of all the sentences such that B is not the theorem of the theory. Subrahmanian, in the 1980s, made use of paraconsistent logic in logic programation [10].

The employing of Evidential Paraconsistent Logic Annotated $\mathrm{E} \tau$ (E $\tau$ Logic $\{\mathrm{XE} "$ Lógica E $\tau$ " \t" - Lógica Paraconsistente Anotada Evidencial E $\tau$ " $\}$ ) has as its main objective implementing computerized systems which allow the handling of uncertain knowledge which can also be inconsistent [11]. The $\mathrm{E} \tau$ Logic treats the premises as partial evidences and presents characteristics of an Evidential Logic where the notes are considered as positive degree of evidence or negative degree of evidence and the analyses take into consideration the value of the information produced by real and uncertain sources [10].

The $\mathrm{E} \tau$ Logic owns a $\mathrm{E} \tau$ language and the atomic propositions are the type $\mathrm{p}(\mu, \lambda)$ where $\mathrm{p}$ is a proposition and $\mu, \lambda \in[0.1]$ (closed real unitary interval). For each proposition $\mathrm{P}$ the value of $\mu$ is associated, which indicates the degree of positive evidence of $\mathrm{p}$, and $\lambda$, which indicates the degree of negative evidence of $\mathrm{p}$. The values $\mu, \lambda$ depend on the applications and can undergo changes where $\mu$ can be the degree of positive belief and $\lambda$ can be the degree of negative evidence of the proposition p; also, $\mu$ can indicate the probability of $\mathrm{p}$ to occur and $\lambda$ the improbability of $\mathrm{p}$ to occur [10].

The Logic atomic propositions $\mathrm{p}(\mu, \lambda)$ can be read as: I believe in $\mathrm{p}$ with the positive degree of belief $\mu$ and the negative degree of belief $\lambda$, or the positive evidence degree $\mathrm{p}(\mu)$ and the negative evidence degree $\mathrm{p}(\lambda)[10]$. It is possible to calculate the Degree of Certainty (Gc) from the equation: Gc $=\mu-\lambda$. This degree can also vary from -1 to +1 , and its value corresponds to the distance from the intersection point between the Degrees of Evidence to the line which connects the point $\mathrm{D}=(0.0)$, Paracomplete, to the point $\mathrm{C}=(1.1)$, Inconsistent, according to the Figure 1:

The degree of certainty chosen for this work has been $\mathrm{H}=0.7$, which corresponds to a certainty of $95,5 \%$, and this is considered good for a planning. Lower degrees lessen PPC certainty safety whereas higher degrees become expensive from when it comes to investments to optimize performance. It can be verified that the area inside the certainty zone is the area of the triangle, in that case $=0.3 \mathrm{X} 0.3 / 2$ which results in a surface of area 0.045 , the total area of the graph is the surface of a square $=1 \mathrm{X} 1$ which results in a surface of area 1 . The percentage of certainty area in relation to the total surface is $=1-(0.045 / 1)$ $=0.955$, which gives a $95.5 \%$ certainty, considered to be a good number for a planning. It goes without saying that for stricter values above 0.70 the costs for the intra-organizational network can be equally higher. 


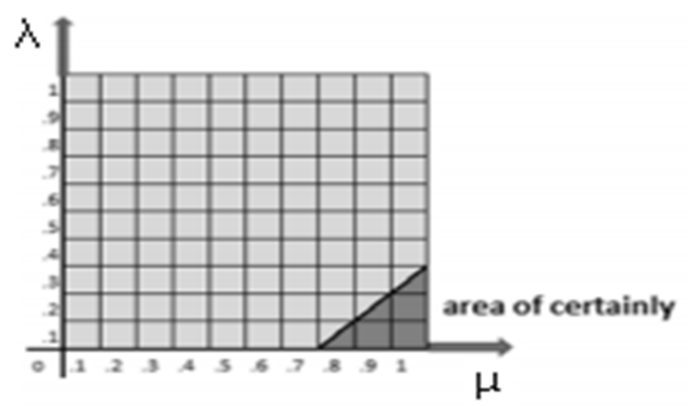

Fig. 1. Region of Certainty in a Cartesian Graph where $0 \leq \mu \leq 1$ and $0 \leq \lambda \leq 1$.

\subsection{Competitive Clusters}

Globalization has contributed to increase more and more competitivity in the market, making viable a great concentration of efforts in the development of businesses in small companies. It is certain that the isolated performance in this market will hardly ever have a globalized reach, with competitive advantages and competition chances $[2,3]$.

In that context, the formation of regional clusters and local productive systems are relevant strategies for the geographic concentration of companies and institutions interconnected on a specific level, involving suppliers, machines, services and infrastructure which make competition viable for the companies $[2,12,13]$.

Clusters are concentration of interconnected companies of a specific sector, encompassing arrangements of related companies and other entities important for competition, including, for instance, specialized raw material suppliers, such as components, machines, services and specialized infrastructure suppliers $[13,14]$.

\subsection{Baby Fashion Cluster}

In Brazilian territory, textile national industry involves about 30 thousand apparels, creating 1.65 million Jobs in all its production chain in the sectors of apparel production with an annual US $\$ 21$ billion profit [15].

The demand for children's products is among the segment which can be explored. More specifically the city of Terra Roxa, the baby wear cluster is still developing, favoring business in the city and in the region.

For its dynamics in the children fashion Field, Terra Roxa has characteristics related to its economical and population dynamics, which needs more attention. The modernization in the rural areas made viable the culture of soy and wheat, using the room which was once used for coffee culture. The failure in agricultural activities forced economic players to look for new products and services [16]. 
The replacement of rural workforce with mechanization contribute to the advent of clusters in the sector of apparel, specially baby wear, as a viable alternative for the economical development of the city, considerably impacting competition, with the creation of new Professional opportunities and Jobs in the companies participating in this segment [16].

The children fashion industries belonging to the studied cluster have an annual production of 3,500,000 articles of clothing, attracting consumers from the Northeastern, northern, southeastern, central western and southern regions of Brazil and Mercosul, creating 1,203 direct formal jobs until 2016. This segment consists of 19 companies acting as manufacturers.

Among them, 16 children fashion producers, seven factions, two service providers, coming to 28 companies, including 250 micro entrepreneurs acting on their own.

\section{Methodology}

The research took place in the cluster of children fashion in Terra Roxa, Paraná, Brazil, which amount to 16 companies totally, characterized by $26 \%$ micro enterprises, $53 \%$ small enterprises and $21 \%$ medium to big enterprises.

From the objective of the work, a descriptive approach has been opted for, with quantitative and qualitative procedures [17] making use of data collection tools such as survey, which is appropriate for this kind of approach $[17,18]$.

Structure interviews were used, with specialists in the management and production from 16 companies belonging to the cluster. Data were gathered personally in the second semester of 2015 and each specialist answered the quantitative and qualitative questions from a pattern $(\mu ; \lambda)$ to determine the level of beliefs and disbeliefs assigned. The data collected were organized in form of tables. The results obtained from the specialists from the same area were considered using disjunction criteria $(\vee)$, where $\mathrm{p} 1(\mu 1 ; \lambda 1) \vee \mathrm{p} 2(\mu 2 ; \lambda 2) \rightarrow \mathrm{p} 1$ or $2(\mu \max ; \lambda \min )$. For results from obtained from specialists from different areas, junction criteria was used $(\wedge)$, where $\mathrm{p} 1(\mu 1 ; \lambda 1) \wedge \mathrm{p} 2(\mu 2 ; \lambda 2) \rightarrow \mathrm{p} 1$ or $2 \mu \min ; \lambda \max )[11]$.

The level of certainty chosen for this work was $\mathrm{H}=0.7$, considered a good number for a planning. It is important to consider that for more restrict values above 0.7 , the costs for the intraorganizational network operations can be high.

\section{Results and Discussion}

\subsection{Planning Premises}

Elements used as premise in the PPC duties were analyzed, as it can be verified in Figure 2.

The analysis from specialists shows that the average or center of gravity of the premises network revealed a 0.85 positive index and 0.15 negative index, resulting in 0.71 index of certainty for this analysis. 


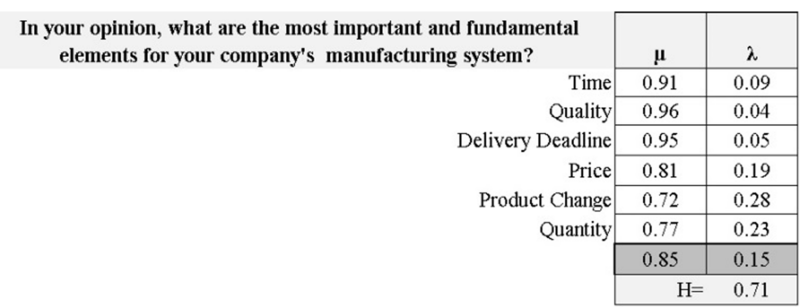

Fig. 2. Planning Premises and Production Control

\subsection{Considerations on Intraorganizational Network}

The Figure 3 shows the relations of the Intraorganizational Network of all the productive sectors considered in the PPC.

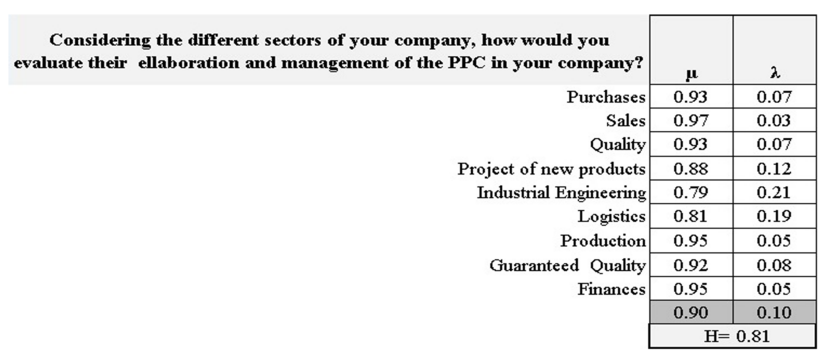

Fig. 3. Considerations of Intraorganizational Network versusPPC

The average of Center of gravity of the Intraorganizational Network has a 0.90 positive index and a 0.10 negative index, resulting in a 0.81 index of certainty for this analysis.

\subsection{Planning Functions}

The PPC encompasses many functions in order to consider all the resources, time/equipment/staff, which bring the PPC result. The Figure 4 illustrates the performance of each function.

According to the analysis, it can be verified that the average or center of gravity of the PPC has a 0.79 positive index and a 0.21 negative index, resulting in a 0.58 index of certainty for this analysis, which, individually, is not a good index of certainty. However, these functions combined with the considerations of premises and of the intraorganizational network result in a global index of certainty which will determine the effectiveness of the PPC.

\subsection{Intersectional Factors}

The Figure 5 reveals the global result among the three individual analyses. 


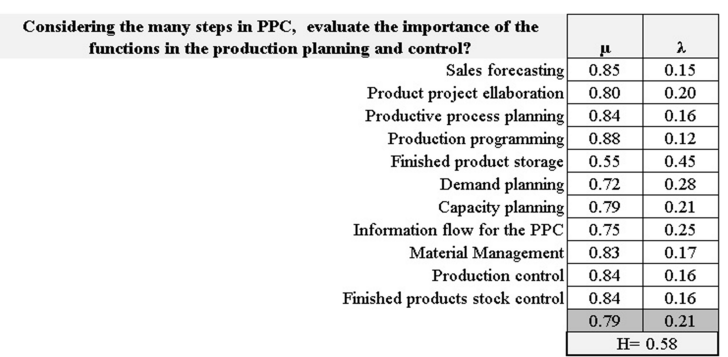

Fig. 4. PPC Functions

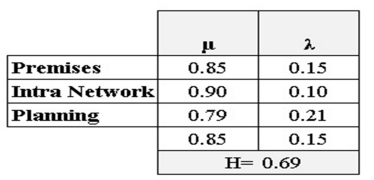

Fig. 5. Influences combined among Premises / Intraorganizational Network / Planning

\section{Conclusions}

The composition of factors reveals a 0.69 index of certainty, which is close to the objective "0.70". That means that the Effectiveness of PPC in the Cluster is consistent, under the prism of Paraconsistent Logic. As a suggestion for the Planning, the item: "Finished Products Storage" should be improved, because it has $\mu=0.55$ e $\lambda=0.45$ becoming $\mu=0.80$ e $\lambda=0.20$. This means a better planning for finished products storage. A new scenario will be had according to Figure 6.

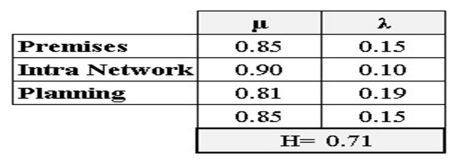

Fig. 6. New efficiency scenario of the PPC

If so, in spite of the functions of the PPC having a low index of certainty individually, 0.58 in that case; the general result of 0.69 is closer enough to the desired 0.70 . Which by itself would show the consistency of the PPC effectiveness. In order to be stricter, a sole item belonging to the PPC should improve, which is finished products storage. This simple improvement can lead the general situation to a 0.70 effectiveness, which according to what was previously mentioned, can provide a $95.5 \%$ guarantee. 


\section{References}

1. Slack, N., Chambers, S., Johnston, R.: Administração da Produção. Atlas (2009)

2. Porter, M.E.: Location, Competition, and Economic Development: Local Clusters in a Global Economy. Economic Development Quarterly 14(1), 15-34 (2000)

3. Tilahun, N., Fan, Y.: Transit and Job Accessibility: An Empirical Study of Access to Competitive Clusters and Regional Growth Strategies for Enhancing Transit Accessibility. Transport Policy 33, 17-25 (2014)

4. Reuter, C., Brambring, F.: Improving Data Consistency in Production Control. Procedia CIRP 41, 51-56 (2016)

5. Costa Neto, P.L.O., Canuto, S.A.: Administraçao com Qualidade: Conhecimentos Necessários para a Gestao Moderna. Blucher (2010)

6. Cichos, D., Aurich, J.C.: Support of Engineering Changes in Manufacturing Systems by Production Planning and Control Methods. Procedia CIRP 41, 165-170 (2016)

7. Volllmann, T., Berry, W., Whybark, D., Jacobs, F.: Sistemas de Planejamento e Controle da Produção. Bookman (2006)

8. Mourtzis, D., Doukas, M., Psarommatis, F.: A Toolbox for the Design, Planning and Operation of Manufacturing Networks in a Mass Customisation Environment. Journal of Manufacturing Systems 36, 274-286 (2015)

9. Behboudi, A.M., Khalilzadeh, A., Youshanlouei, H.R., Mood, M.M.: Identifying and Ranking the Effective Factors on Selecting Enterprise Resource Planning (ERP) System Using the Combined Delphi and Shannon Entropy Approach. Procedia-Social and Behavioral Sciences 41, 513-520 (2012)

10. Abe, J.M., Lopes, H.F., Nakamatsu, K.: Paraconsistent Artificial Neural Networks and Delta, Theta, Alpha, and Beta Bands Detection. In: Advances in ReasoningBased Image Processing Intelligent Systems, pp. 331-364. Springer (2012)

11. de Carvalho, F.R., Abe, J.M.: A Simplified Version of the Fuzzy Decision Method and its Comparison with the Paraconsistent Decision Method. In: Computing Anticipatory Systems: CASYS '09: Ninth International Conference on Computing Anticipatory Systems. vol. 1303, pp. 216-235. AIP Publishing (2010)

12. Reis, J.G.M., Neto, M.M., Vendrametto, O., Costa Neto, P.L.O.: Qualidade em Redes de Suprimentos: A Qualidade Aplicada ao Suplly chain Management. Atlas (2015)

13. Amato Neto, J.: Gestão de Sistemas Locais de Produção e Inovação (Clusters/APLS): um Modelo de Referencia. Atlas (2009)

14. Söylemezoğlu, E., Doruk, Ö.T.: Are Clusters Efficient for the Relation Between Milk Production and Value Added per Capita in Regional Level? An Empirical Assessment. Procedia-Social and Behavioral Sciences 150, 1277-1286 (2014)

15. IBGE: Instituto Brasileiro de Geografia e Estatísticas: Demografia das Empresas. IBGE (2016)

16. Willers, E.M., Lima, J., Staduto, J.A.R.: Desenvolvimento Local, Empreendedorismo e Capital Social: O Caso de Terra Roxa no Estado do Paraná. Interações 9(1), 45-54 (2008)

17. Collis, J.: Pesquisa em Administração: Um Guia Pratico para Alunos de Graduação e Pos-graduacao. Bookman (2005)

18. Hahn, M.H., Lee, K.C., Lee, D.S.: Network Structure, Organizational Learning Culture, and Employee Creativity in system Integration Companies: The Mediating Effects of Exploitation and Exploration. Computers in Human Behavior 42, 167$175(2015)$ 